\title{
La penitencia de don Quijote y la experiencia literaria moderna
}

\author{
JAVIER DE LA HIGUERA*
}

\author{
A Pedro Cerezo, \\ ejemplo de honestidad intelectual y vital
}

\begin{abstract}
Resumen
El episodio de Sierra Morena, en el Quijote, ofrece claves importantes para entender en qué sentido la novela de Cervantes se puede considerar el prototipo de la obra literaria moderna. La penitencia de don Quijote se puede entender como prefiguración de la experiencia literaria moderna y don Quijote como «figura» (Auerbach) del escritor moderno. La hipótesis se desarrolla analizando tres cuestiones: en primer lugar, el problema de la imitación, tema específicamente literario de que se ocupa el episodio en relación con la parodia de los libros de caballerías y su «simulación táctica» (Robert); en segundo lugar, la singular penitencia de don Quijote, en que se pone en juego una paradójica experiencia del absoluto como absoluto literario; por último, atendiendo a la identidad específicamente literaria que don Quijote adquiere en ese episodio, por la que cabe interpretar al héroe cervantino como figura por excelencia del escritor.
\end{abstract}

Palabras clave: literatura moderna; parodia; melancolía; experiencia originaria; absoluto literario; locura poética.

Title: Don Quixote's penitence and the modern literary experience

\begin{abstract}
The episode of Sierra Morena, in the Quixote, offers important keys to understand in what sense Cervantes' novel can be considered the prototype of the modern literary work. Don Quixote's penitence can be understood to mean a prefiguration of the modern literary experience and don Quixote, the «figure» (Auerbach) of the modern writer. The hypothesis has been developed by analyzing three issues: first, the problem of imitation, a spe-

* Grupo de Investigación «La imagen barroca del mundo» (HUM-188). Departamento de Filosofía II. Universidad de Granada.jdelahiguera@ugr.es / ORCID iD: https://orcid.org/0000-0001-93508580 .
\end{abstract}


cifically literary subject of the episode, in relation to the parody of the chivalric romance and its «tactical simulation» (Robert); second, the singular penitence of don Quixote, in which a paradoxical experience of the absolute as literary absolute is put into play; finally, the specifically literary identity that don Quixote acquires in that episode, by which it is possible to interpret the cervantine hero as the prime figure of the writer.

Keywords: Modern literature; Parody; Melancholy; Original Experience; Literary Absolute; Poetical Madness.

\section{Cómo citar este artículo / Citation}

De la Higuera, Javier (2018). «La penitencia de don Quijote y la experiencia literaria moderna», Anales Cervantinos. 50, pp. 279-296, https://doi.org/10.3989/anacervantinos.2018.012.

\section{EL VALOR DEL EPISODIO DE SIERRA MORENA}

La importancia del episodio de Sierra Morena en el Quijote se atestigua desde el punto de vista de la historia literaria externa por las diversas adaptaciones de las que muy pronto fue objeto, entre otras: el Cardenio perdido de Shakespeare y Fletcher, de 1613, Les folies de Cardenio de Pichou, de 1628, el Dom Quixote de Guérin de Bouscal, de 1639, o aquí en España, el Don Quijote de Guillén de Castro, de 1606. Más allá de estas circunstancias, la crítica ha reconocido el valor central de este pasaje en la economía de la obra de Cervantes ${ }^{1}$. Pero entre la historia externa de la obra y su estructura interna, puede que el episodio encierre claves importantes para entender cómo la obra de Cervantes ha contribuido a forjar la literatura moderna. Puede que tengamos en él algo más que una metáfora de la experiencia literaria moderna, quizás una figura, en el sentido que Auerbach (1998) ha descubierto de esta palabra: a la vez su imagen plástica o sensible y su prefiguración real. Desde esa perspectiva, don Quijote es sobre todo, en ese episodio, la figura del escritor moderno ${ }^{2}$.

Tratar acerca de la importancia del Quijote o de uno de sus episodios es siempre algo difícil y paradójico porque a esa importancia siempre está unida la insignificancia del tema, como si las razones del valor objetivo de la obra, así como de su éxito posterior, permanecieran ocultas o disueltas en las cosas intrascendentes que la novela cuenta. Una obra, además de aquello que dice, puede contener en silencio el principio generador de otros textos y de otras

1. Sobre las adaptaciones posteriores del episodio, puede verse: Chartier (2010), Bardon (2010: 293-300) y Sánchez (1999: 64). Sobre la importancia de este pasaje en la obra: Avalle-Arce (1970: 253), Riley (1989: 114) y Sánchez (1989: 95-96).

2. Atlee (1986) ha propuesto una interpretación del nombre «caballero de la triste figura» en el sentido señalado por Auerbach, con la finalidad de evitar una simple interpretación cómica del episodio y atender al aspecto también trágico que encierra. Sin embargo, Atlee da un valor religioso a este aspecto serio sin plantear en qué medida la «figura» de don Quijote es, por ello mismo, esencialmente literaria. 
obras, siendo su condición histórica de posibilidad. En este sentido, como Foucault propuso en relación con obras como la Interpretación de los sueños de Freud, o El Capital de Marx, puede haber determinadas obras «fundadoras de discursividad», que son capaces de establecer «la posibilidad y la regla de formación de otros textos» (Foucault 1994b: 804). La posición «transdiscursiva» del Quijote es comúnmente señalada, aunque no sea fácil determinar qué es lo que ello implica: «Falta un libro — se lamenta Ortega y Gassetdonde se demuestre que toda novela lleva dentro, como una íntima filigrana, el Quijote» (2001: 242). Mostrar por qué la obra de Cervantes es «la primera novela en el orden del tiempo y del valor» (Ortega y Gasset 2001: 179) quizás sólo es posible buscando dentro de ella lo que la pone en contacto con el exterior, más una negatividad que una positividad, persiguiendo el espacio de resonancia o de repetición que la constituye como obra singular pero que al mismo tiempo exige su prolongación infinita en otras obras, también por ello afectadas por esa misma estructura de repetición. El episodio de la penitencia de don Quijote en Sierra Morena quizás sea, en este sentido, la filigrana en la que se encierra todo el Quijote en tanto que prototipo de la obra literaria moderna: filigrana, pues, de la filigrana ${ }^{3}$. Tres cuestiones, y el avance de sus respectivas respuestas, pueden guiar el desarrollo de esta hipótesis:

En primer lugar, ¿cuál es realmente el tema o asunto del episodio de la penitencia en Sierra Morena? El tema o asunto del episodio es literario: la imitación. En segundo lugar, ¿qué está en juego en la imitación de don Quijote? La imitación es una experiencia del absoluto - de la literatura como absoluto-. Y, por último, ¿qué identidad adquiere don Quijote a través de su imitación? Don Quijote es la figura del escritor moderno. Veámoslo.

\section{EL PROBLEMA DE LA IMITACIÓN}

Es importante reparar en que en este episodio las aventuras de don Quijote se convierten en acciones consciente y voluntariamente artísticas: su sentido e intención es imitar modelos, tal y como en el arte y en la literatura era norma tradicional (Riley 1989: 109-112; 2000: 82). Se podría decir que a través de este desplazamiento hacia la cuestión de la imitación, Cervantes convierte a la historia literaria anterior y a la propia literatura en el tema

3. Desde el punto de vista de la historia general de la cultura moderna, el valor instituyente del Quijote podría encontrarse, como ha sugerido Kundera (1996: 16-18), en que Cervantes, por primera vez en esta obra, habría sabido dar la palabra al mundo de la vida (Lebenswelt), a la existencia concreta y pre-objetiva, más profunda y radical que la naturaleza matematizada, configuradora de la realidad desde Descartes y en toda la modernidad. Y que, con ello, habría originado una institución, la literatura moderna, que ha corrido subterráneamente pero en paralelo a la ciencia y a la técnica diciendo verdades que estas no podían decir. El papel de la obra de Cervantes como «obertura del mundo moderno» ha sido estudiado recientemente por Cerezo (2016) persiguiendo como clave la «potencia simbólica» del texto cervantino y, en particular, la figura de don Quijote como símbolo poético del principio moderno de subjetividad. 
principal de este episodio, más allá de las peripecias y de la trama argumental de la narración. La «inyección de materia literaria» (Márquez Villanueva 2011: 23) que aquí se produce le permite realizar una operación que, como sabemos, es característica de la obra literaria moderna: al tiempo que dice su fábula, la obra dice en silencio también su «tras-fábula» (Foucault 1994a), dando de ese modo señas de lo que es la literatura. La noción de imitación adquiere por ello una enorme ambigüedad. La imitación de don Quijote es la perfecta reactualización del código caballeresco: «Todo cuanto yo he hecho, hago e hiciere va muy puesto en razón y muy conforme a las reglas de la caballería, que las sé mejor que cuantos caballeros las profesaron en el mundo» (cap. 25, p. 273) ${ }^{4}$. La elección de los modelos a imitar, fundamentalmente Amadís: presentado como el más perfecto, el único y original, y reducido al acto en que se concentra su ejemplaridad, el retiro a la Peña Pobre, y en su cambio de nombre al «nombre significativo» (p. 275) de Beltenebros, da a la imitación de don Quijote el valor de una reactualización del modelo literario en el plano de la cotidianidad. Pero a través de esa imitación se produce una doble transformación: don Quijote literaturiza su vida pero, al mismo tiempo, realiza la literatura en ella. Don Quijote parece concebir aquí su profesión de caballero no tanto en clave ética sino «desde un ángulo estético» (Finello 1980: 242). Allí encuentra la ocasión para ensayar «su tentativa más rebuscada y desesperada de vivir la ficción literaria» (Riley 1989: 114). La imitación de los modelos no solo produce entonces la alienación de la vida de don Quijote en la literatura sino, lo que es quizás más importante, la materialización de la literatura en la vida. Gerhardt (1955: 34-35) ya llamó la atención del hecho de que la originalidad de don Quijote no está en querer escribir un libro de caballerías sino en querer vivirlo: la literatura como acción y como vida. El episodio imitativo de Sierra Morena no sería principalmente la muestra del ejercicio literario de don Quijote, cuyos deseos literarios se habían declarado desde el principio de la obra, sino sobre todo la presentación de un ejercicio literario que es afirmado como la verdadera vida.

La ambigüedad de la imitación de don Quijote es también lo que explica que el modelo de Amadís aparezca mezclado con el de Roldán (del Orlando furioso, de Ariosto), las «locuras de lloro y sentimientos» del primero con las «locuras de daño» del segundo, si bien finalmente don Quijote, en una reflexiva deliberación posterior, se decantará por el primero. La imitación de los modelos caballerescos de Amadís y Roldán se traduce en don Quijote en un deliberado volverse loco pero, aunque Amadís y Roldán tenían una causa para su locura o penitencia, don Quijote no la tiene o, mejor dicho, se trata de la ausencia de causa como causa. Las palabras de don Quijote en el cap. 25 son extraordinarias:

Ahí está el punto — respondió don Quijote- y esa es la fineza de mi negocio, que volverse loco un caballero andante con causa, ni grado ni gra-

4. Se cita el Quijote por la edición de F. Rico en Instituto Cervantes-Crítica. 
cias: el toque está en desatinar sin ocasión y dar a entender a mi dama que si en seco hago esto ¿qué hiciera en mojado? (cap. 25, p. 276).

Es precisamente su carácter inmotivado e inútil lo que hace de su penitencia la hazaña máxima o perfecta, una hazaña superior a las anteriores: «Tan rara, $\tan$ felice y tan no vista imitación» (p. 276) ${ }^{5}$. Cuando más adelante el cura y el barbero juzgan la penitencia de don Quijote y la tildan de «inútil» (cap. 26, p. 298) y de «vana» (cap. 27, p. 300), dicen algo que es estrictamente cierto y que hasta el mismo don Quijote habría admitido. Porque lo característico de la penitencia imitativa de don Quijote es precisamente su gratuidad o intransitividad: «Ni grado ni gracias», ni por placer ni por mérito. Su hazaña pone incluso a don Quijote más allá de la vida orgánica o natural: es significativo que después de afirmar lo elevado de su hazaña, don Quijote asocie la gratuidad de su acción al rechazo del alimento o a comer solo hierbas, es decir, el rechazo de aquellas actividades necesarias para el sustento vital, como si a través de la repetición de sus modelos se llevara a cabo la acción máxima por la que un ser mortal se pone por encima de su vida y de su muerte terrenas, en una existencia superior que es la existencia literaria. Blanchot (1969) señaló, en ese sentido, que la locura del propio Cervantes es mayor aún que la de don Quijote: «Escribir sin vivir», aunque en referencia a este pasaje que comentamos don Quijote aparece aquejado precisamente de esa locura de escritor, que es la de Cervantes ${ }^{6}$.

Amadís y Roldán, con su locura penitencial, respondían a la ausencia real de sus respectivas amadas, realmente existentes para ellos, pero carecían de la conciencia literaria que posee don Quijote, quien obedece en su acción a modelos literarios convertidos en absolutamente reales, y responde con su locura a una ausencia mucho más radical, dando testimonio de ella. ¿Cuál es esta ausencia? La fábula la presenta como la ausencia de su amada Dulcinea pero podemos preguntarnos por qué ha de ser más radical esta ausencia que la que podía representar la de las amadas de los otros caballeros conocidos. Parece que una conciencia melancólica, de pérdida de un orden pleno de realidad, está en la base del espíritu literario cervantino, traducido aquí en la relación que don Quijote establece con sus modelos imitativos. Conciencia de que el mundo está tocado por su falta de razón y de fin, por su falta de necesidad, por su gratuidad, en suma, literalmente surgido de la nada. Y solo

5. «... el [deseo] que tengo de hacer en ellas una hazaña con que he de ganar perpetuo nombre y fama en todo lo descubierto de la tierra; y será tal, que he de echar con ella el sello a todo aquello que puede hacer perfecto y famoso a un andante caballero» (p. 273).

6. «Don Quijote no es razonable, aunque es lógico, si piensa que la verdad de los libros es buena también para la vida y si se pone a vivir como un libro, aventura maravillosa y decepcionante, puesto que la verdad de los libros es la decepción. Para Cervantes, las cosas son de otro modo porque para él Don Quijote no se esfuerza en descender a la calle con el fin de poner en práctica la vida de los libros, es en un libro aún donde se esfuerza, sin dejar su biblioteca y no haciendo nada, al vivir, al moverse, al morir, más que escribir sin vivir, sin moverse ni morir. (...) Sorprendente locura, risible y perversa sinrazón la que disimula toda cultura, pero que es también su verdad oculta, sin la cual no se edificaría y sobre la cual se edifica majestuosa y vanamente» (Blanchot 1969: 569). 
ante esa nada se hace posible la búsqueda de un absoluto de segundo orden, que es literario, que va a ser la literatura moderna. En este sentido, el carácter precursor de la literatura moderna que posee el Quijote tendría que ver con la manera en que está estructuralmente presente en ella ese rasgo melancólico, de manera que este sería precisamente la clave de su poder generativo, tal como han señalado algunos intérpretes (García Gibert 1997; Cerezo 2006; de la Higuera 2013; Thiebaut 2016). La hazaña penitencial de don Quijote pudiera ser en cifra la acción por excelencia que consiste en hacer un mundo, verdadera «acción revolucionaria» (Blanchot 1981), contenida sin embargo en las modestas páginas de cada obra literaria moderna.

El tema de estos pasajes, decíamos, es literario, la imitación de los modelos que proporcionan los libros de caballerías. Estos son elevados al máximo de realidad, hasta el punto de ser sacralizados y convertidos en objeto de profesión de fe religiosa. Pero, al mismo tiempo, son parodiados. Es patente que la novela de Cervantes opera la disolución paródica del código caballeresco, integrado de manera desmitificada en su «narración de la prosa de la vida» (Rodríguez 2003: 142). En las Meditaciones del Quijote, Ortega subrayó la necesidad de interpretar la obra de Cervantes desde la óptica de su relación polémica con los libros de caballerías. La realidad cotidiana de la que habla en general la novela se construye como tema literario precisamente en su diferencia con este plano épico de realidad absoluta del que hablaban las caballerías, ese «último grande retoñar del viejo tronco épico» (Ortega y Gasset 2001: 203). La novela de Cervantes sería lo contrario de la épica pero, al mismo tiempo, incorporaría la realidad épica en tanto que desaparecida, integrándola negativamente y llevando a cabo su «intususcepción» (2001: 216). La simulación de penitencia que don Quijote hace en estas páginas que comentamos, toda esa «máquina de penitencia», como la llama el propio Sancho en el capítulo 25 (p. 280), es expresión de un juego, como algunos intérpretes han visto bien (Torrente 1975; Bloom 1995; Yushimito 2010). Pero, no lo olvidemos, es también la «simulación táctica» (Robert 1963: 35) que Cervantes lleva a cabo de los libros de caballerías y de toda la gran tradición épica. Si admitimos que la obra de Cervantes es una parodia lúdica, no hay que olvidar que la parodia es un fenómeno intertextual en que un sistema literario se superpone a otro, recodificando sus elementos y sometiéndolos a nuevas reglas, operación de la cual surge algo nuevo (Cortázar 1984: 62).

En el episodio de Sierra Morena, esa intertextualidad aparece expresamente señalada al identificar expresamente los modelos literarios de la imitación; la re-funcionalización que en él se produce de los elementos caballerescos, dejando de estar orientados al llanto para estarlo a la risa (Márquez Villanueva 2011: 52), es muestra de que el juego quijotesco es aquí bastante más que un juego. Fernández Turienzo (1983) lo ha mostrado a propósito del «pasaje más oscuro» del Quijote, en relación con el juicio que el cura hace del Tirante el Blanco en el capítulo 6 de la primera parte: las «necedades de industria» de las que allí se habla son los fingimientos o ficciones hechas, no solo con propósito consciente, sino con intención expresamente artística, y que son el 
producto del «don poético por excelencia» (1983: 55). De esas «necedades de industria» sería un ejemplo expreso la penitencia que don Quijote realiza en Sierra Morena, la cual, si es verdad que no deja de ser un «simulacro de penitencia» (Hutchinson 1998: 293) inmotivado, es a otro nivel, y precisamente a causa de ese carácter gratuito, un acto que reclama para sí un valor absoluto. En alusión crítica a la interpretación que Rodríguez Marín hizo de las locuras «de mentirijillas» del capítulo 25, Maldonado de Guevara (1973) señaló la profunda comprensión que Guillén de Castro tuvo del ingenio quijotesco: «Ingenio locura es» dice el verso, es decir — interpreta Maldonado-, la «locura trascendental y ficcional» del furor poético ${ }^{7}$. La insistencia de don Quijote ante Sancho, de que en sus locuras imitativas se trata de calabazadas «verdaderas, firmes y valederas» (cap. 25, p. 281), habría pues que tomarla completamente en serio.

\section{LA EXPERIENCIA DEL ABSOLUTO LITERARIO}

Pero tendríamos que preguntarnos aún - y este es nuestro segundo temaqué se juega realmente en la hazaña quijotesca de este episodio de la penitencia en Sierra Morena, de qué experiencia se trata. Es importante reparar en el lugar de la penitencia, la sierra, de cuyo valor simbólico se ha ocupado abundantemente la crítica ${ }^{8}$. Don Quijote ve enseguida que se trata de «lugares acomodados para las aventuras que buscaba» (cap. 23, pp. 250-251), aunque pronto se revele como el lugar de una aventura distinta a las demás y por ello crucial. Se trata de un lugar separado, en discontinuidad radical con los otros lugares, que ha dejado de ser un escenario natural para convertirse en literatura (Márquez Villanueva 2011: 42). Pero veamos cuál puede ser el sentido de esa discontinuidad y de esa conversión literaria. Algunos elementos a tener en cuenta: el simbolismo ascensional de la sierra, de connotaciones espirituales, frente a la llanura manchega, la búsqueda de las entrañas de la sierra, el laberinto, lugar al que no conduce ningún camino, inhabitable, pocas veces pisado, etc. Lugar de sorpresas y de encuentros, ahora no solo con personas - Cardenio o Dorotea-, sino también con cosas como la maleta. Lugar, pues, de una experiencia que no es cotidiana sino, podríamos decir, en algún sentido, trascendental. Más que mero locus amoenus, y con resonancias añadidas a las del laberinto, el lugar de Sierra Morena es asimilable al desierto, ese «lugar sin lugar» donde en cierto modo se comienza a existir: «Momento de desnudez y de desprendimiento que está en el origen de la existencia justa»

7. Los versos de Guillén, citados por Maldonado de Guevara (1973: 175), son estos: «Más, sin furia, poco a poco,/ una locura discreta/ quiero hacer: seré poeta/ para ser discreto y loco./ Ingenio locura es,/ que quien por naturaleza/ hace pies con la cabeza/ el mundo traerá a los pies» (Don Quijote de la Mancha, acto III, escena 13).

8. Se pueden mencionar, entre otros, los estudios de Herrero (1981), Jiménez Fajardo (1984), Resina (1989), Pagán (1997) y Chiong Rivero (2006). 
(Blanchot 1959: 111). ¿Qué experiencia original va a ocurrir en ese «espacio sin lugar» que es Sierra Morena? No se trata de la mera experiencia de un sujeto, en el sentido habitual de la palabra. En realidad, ninguna experiencia de nuestro héroe lo es: las suyas son experiencias de las que no aprende nada y de las que no saca escarmiento, como le recuerda Sancho al comienzo del capítulo 23: «Así escarmentará vuestra merced — respondió Sancho- como yo soy turco» (p. 248). Pero en el episodio que comentamos se trata de esa experiencia quijotesca en su estado puro; más aún, podríamos decir, como ya hemos sugerido, que la experiencia que hace allí don Quijote es la experiencia originaria - o de lo originario - . Don Quijote, va «embebido y transportado en la memoria de sucesos memorables» (p. 251), a diferencia de Sancho - el texto se encarga de remarcarlo-, que está solo al cuidado de su estómago. Frente a la aventura «de provecho», como dice el escudero, la auténtica aventura quijotesca no sirve para nada, sino que es una experiencia intransitiva no referida a las cosas mundanas. Los dos encuentros sorpresivos iniciales, ocurridos al llegar a la sierra, con la maleta y con Cardenio, son «ocasión» de esa experiencia absoluta o de lo absoluto:

Por un lado, la maleta abandonada y cerrada con candado pero rota, hace pensar en un arcano, sin embargo, abierto o mostrado. En su interior, hay cosas valiosas: tejidos finos, que informan de la elevada posición social de su dueño y permiten una primera hipótesis sobre su identidad; y el dinero, recibido jubilosamente por Sancho y que le hace pensar en que por fin se las ve con una aventura de provecho. El lector percibe también por contraste con este valor monetario que la maleta posee sin embargo un valor muy superior al económico, cifrado quizás en el «librillo de memoria» contenido en ella, y que va a ser el hilo conductor de la experiencia de don Quijote y clave de su significado. El librillo tendrá el doble valor de ser testimonio de ausencia y apelación a la presencia: en el librillo están escritos un soneto de amor despechado escrito por su dueño, así como una «carta misiva» dirigida a su amada, lo que permite pergeñar a don Quijote y a Sancho una segunda hipótesis sobre el dueño de la maleta, imaginado ahora como «algún desdeñado amante» (p. 254). La vista de esos escritos probablemente abre también el apetito de escritor de don Quijote (Salinas 1989: 118).

Respecto a Cardenio, en cuanto aparece saltando con ligereza y desnudo, don Quijote tiene la certeza de que es el dueño de la maleta. En ese momento se produce el cara a cara de Cardenio y don Quijote en una escena memorable y tierna conocida por todos. El reconocimiento que don Quijote hace de Cardenio y la aparición de los «nombres significativos», reductores de los personajes a su esencialidad, de «caballero de la triste figura» y de «el roto de la mala figura», no deja lugar a dudas para el lector: don Quijote y Cardenio son la misma persona, desdoblada, duplicada, en una mezcla de familiaridad y extrañeza que tiene algo de siniestro o inhóspito —unheimlich, en el lenguaje de Freud- . No olvidemos que don Quijote es un personaje en busca de su identidad y en estos pasajes parece encontrarla. A través de la 
identificación con Cardenio, don Quijote - y el propio lector - adquiere una claridad sobre su propia locura, ya que en Cardenio ve realmente una objetivación exterior de la misma: la locura de ambos se debe a una pérdida, la que supone la «luenga ausencia» (cap. 25, p. 279) de la amada. Es la locura de un amor absolutizado, mucho más que un mero sentimiento. Cardenio habla en el segundo de sus relatos del «verdadero amor», que es eterno (p. 263), y da de su amada Luscinda una versión, como la que don Quijote da de Dulcinea, también absolutizada: en ella «se encumbran todas las gracias de la hermosura y del entendimiento repartidas por todas las mujeres del mundo» (cap. 24, p. 267).

En todo este episodio se trata, pues, de la experiencia muy problemática de un absoluto, en la que este es experimentado en tanto que ausente. Experiencia no meramente nostálgica o ideal sino de carácter sensible; cabe, como apuntó F. Schlegel en los Fragmentos del Lyceum, una «sensibilidad negativa»: «Se puede amar algo fervorosamente justamente porque no se posee» (1994: 57). Es el caso de don Quijote, quien hace de la experiencia de ese amor absoluto la hazaña de las hazañas. La penitencia es tanto experiencia de testimonio de ese absoluto ausente como de llamada o apelación a su presencia o comparecencia ${ }^{9}$. Así lo era en el caso de los versos y de la carta misiva, compuestos por Cardenio en el librillo de memoria, así va a ser en la carta enviada por don Quijote a Dulcinea y en los testimonios de su penitencia que espera que Sancho le lleve. Sabemos de la transformación paródica que esa experiencia de absoluto, mezcla de ausencia y de presencia, sufre en la obra: don Quijote le pide a Sancho que vea, con objeto de dar fe de ellas, una o dos docenas de locuras, que hará en menos de media hora, y que lo vea en cueros. El envío a Dulcinea a través de la carta, es verdad que se dirige a una persona real que vive en El Toboso, pero todos sabemos, hasta el mismo don Quijote, que solo se identifica con Dulcinea por un acto de fe; además, esa identificación quedará suspendida de innumerables maneras: Sancho no llega al Toboso, se inventa el encuentro con Dulcinea, lo cuenta luego despiadadamente como el encuentro con la rústica Aldonza, etc. Pero la carta de don Quijote, estando tocada por la nada, fallida desde el principio hasta el final - carta dirigida a una mujer inexistente, que además no sabe leer, olvidada por su mensajero, desfigurada luego por la memoria, inventada la manera en que su destinataria la recibe, sin querer leerla, aceptado por un acto de fe su contenido, etc.- - es también, en cierto sentido, la carta de amor por excelencia, carta de una plenitud de amor correspondido, en que la absoluta afirmación amorosa del amante envuelve necesariamente la respuesta afirmativa de la amada. Pedro Salinas la consideró por ello como «la mejor carta de amores de la literatura española»: «La amada se ha transformado en el Amado. Dulcinea existe unida a don Quijote, en él, solo en él. De tanto quererla el caba-

9. Hutchinson (1995: 294) ha visto que se trata de un «acto restaurativo», una especie de contrato unilateral por el que se quiere obligar a Dulcinea a comparecer. 
llero, ha hecho que le quiera. De tenerla tanta fe, la ha dado fe. De desear que exista, la ha hecho existir» (Salinas 1989: 124).

Es verdad que el modo de existencia de Dulcinea plantea al lector muchos problemas. Como los demás elementos del código caballeresco, Dulcinea pertenece a un régimen de auténtica realidad, definida por inversión con lo que llamaríamos nosotros - y Sancho, y los demás personajes noquijotescos- «real»: «Lo que real y verdaderamente es» (p. 278), no es lo que por encantamiento nos parece que es y llamamos real, de manera que lo verdaderamente real es lo que nos parece que no lo es ${ }^{10}$. En esta existencia de idealidad más que real, que posee Dulcinea, se podría descubrir un rasgo de modernidad en el pensamiento de Cervantes, equiparable en este sentido a Galileo o Descartes y a la nueva mentalidad científico-natural (Duque 2006). La idea proyectiva de experimento que esta nueva mentalidad pone en juego consiste en una concepción de la mente capaz de «generar prototipos irrealizables, pero presuntamente reguladores e inspiradores de cotidianos quehaceres» (Duque 2006: 17-18). Pero habría indicios también para pensar que la clave que maneja Cervantes aquí es teológica o religiosa $y$ que, de alguna forma, Dulcinea representa simbólicamente a Dios: en la penitencia de don Quijote se encerraría una experiencia de Dios de carácter negativo, en forma de testimonio de su ausencia ${ }^{11}$; el envío, a través de Sancho, dirigido a Dulcinea, del que se espera una respuesta, sería interpretable en ese sentido como una apelación dirigida a Dios, la petición de una prueba de su presencia o, incluso, podríamos pensar, una singular prueba de su existencia, en este caso experimental y no meramente lógica como las de los teólogos. De esta forma, la penitencia de don Quijote se asemejaría a la experiencia desértica del profeta: en el lugar sin lugar en que nos encontramos, la sierra, don Quijote, como el profeta, atravesaría la negatividad divina y se instalaría en un espacio inhóspito desde el que lanza una palabra que ya no es suya porque procede de la absoluta y exterior presencia, del afuera, palabra del afuera

10. Recordemos el famoso pasaje: «Mira, Sancho, por el mismo que denantes juraste te juro — dijo don Quijote - que tienes el más corto entendimiento que tiene ni tuvo escudero en el mundo. ¿Que es posible que en cuanto ha que andas conmigo no has echado de ver que todas las cosas de los caballeros andantes parecen quimeras, necedades y desatinos, y que son todas hechas al revés? Y no porque sea ello ansí, sino porque andan entre nosotros siempre una caterva de encantadores que todas nuestras cosas mudan y truecan, y las vuelven según su gusto y según tienen la gana de favorecernos o destruirnos; y, así, eso que a ti te parece bacía de barbero me parece a mí el yelmo de Mambrino y a otro le parecerá otra cosa. Y fue rara providencia del sabio que es de mi parte hacer que parezca bacía a todos lo que real y verdaderamente es yelmo de Mambrino, a causa que, siendo él de tanta estima, todo el mundo me perseguiría por quitármele, pero como ven que no es más de un bacín de barbero, no se curan de procuralle...» (cap. 25, pp. 277-278).

11. Riley (1989: 111) deduce de la inexistencia de Dulcinea, quizás apresuradamente, que la dama no puede ser la «verdadera causa motriz» de la penitencia cuando parece más bien, al contrario, que la penitencia sólo puede entenderse como experiencia de la ausencia de una realidad plena o ideal y, por tanto, como consecuencia de su inexistencia real-cotidiana. 
que la palabra profética repite, con la cual entra en reciprocidad y de la cual es la «mímica viviente» (Blanchot 1959: 117) ${ }^{12}$.

Unamuno llamó la atención del carácter místico y contemplativo del episodio de Sierra Morena y, como es sabido, comparó aquella penitencia con la de Ignacio de Loyola en la cueva de Manresa. Pero más allá de las posibles analogías religiosas o de los rasgos de modernidad naturalista, que antes veíamos, el «Caballero de la Fe» (Unamuno 1988: 157), parece ser en estos pasajes de la penitencia en Sierra Morena el caballero de una fe nueva y especial, como lo es la literaria, y el profeta de un acontecimiento por venir, que es la literatura moderna ${ }^{13}$. La experiencia de absoluto que allí se produce es por ello la de un absoluto solo literario —o la de la literatura como único absoluto - . Desde esta nueva experiencia literaria, la referencia teológica es transfigurada, tanto si se la interpreta en positivo como valor simbólico de la figura de Dulcinea, como en negativo, si esa referencia tiene un valor paródico y encierra la crítica de Cervantes a la teología ortodoxa de la época. La fe que don Quijote tiene en Dulcinea, aun a sabiendas de que es Aldonza, es efectivamente una fe, pero es el tipo de fe que define a la literatura, la misma que tenemos cuando en la lectura de una novela nos identificamos plenamente con uno de los personajes o la trama consigue provocar en nosotros el

12. Cito dos pasajes de Blanchot (1959) para ilustrar esta interpretación de la palabra profética que, no obstante, Blanchot no relaciona con don Quijote: «El desierto es este afuera donde no podemos permanecer puesto que estar allí es estar ya afuera, y la palabra profética es entonces esa palabra en que se expresaría con una fuerza desolada la relación desnuda con el Afuera, cuando no hay todavía relaciones posibles, impotencia inicial, miseria del hambre y del frío, que es el principio de la alianza, es decir, un intercambio de palabra donde se libera la sorprendente justicia de la reciprocidad» (p. 111); «La palabra profética es originalmente diálogo. (...) Pero lo es de una manera más esencial en la medida en que no hace más que repetir la palabra que le es confiada, afirmación en que se expresa entonces por una palabra comenzante lo que sin embargo ya ha sido dicho. Es esa su originalidad. Esa palabra es primera y sin embargo hay siempre ya antes que ella una palabra a la que responde, repitiéndola. Como si toda palabra que comienza, comenzara por responder, respuesta en que se oye, a fin de ser reconducida hacia el silencio, la palabra del Afuera que no cesa» (p. 114).

13. En su ensayo de 1938, Figura (Auerbach 1998), E. Auerbach reconstruyó la historia conceptual de esta expresión, descubriendo el nuevo sentido que adquiere en el contexto cultural cristiano, determinante de toda una concepción del acontecer histórico. Más allá de la comprensión de la figura como imagen plástica o configuración externa, como encontramos en Terencio o Varrón, o de la imagen que es diferente de la mera representación, en Cicerón, o de la figura retórica de Quintiliano, los padres de la Iglesia introducen un nuevo sentido por el que la figura es «profecía real o representación anticipadora de algo futuro» (1998: 69); la figura es, en este sentido, algo real e históricamente existente que anuncia o prefigura algo igualmente real e histórico. Por ejemplo, en Tertuliano, Adán es figura Christi y Eva es figura Ecclesiae o, en general, se consideran las personas o acontecimientos del antiguo testamento como figuras o profecías del nuevo. Pero la figura, en este sentido, es algo más que una mera alegoría: «La figura posee la misma realidad histórica que lo profetizado en ella» (1998: 70), de ahí que haya que concebirla no como mera realidad espiritual sino en su concreta sensorialidad, la cual exige para la figura su consumación carnal (1998: 75). Según la hipótesis que en este artículo se presenta, la relación entre la obra de Cervantes y la literatura moderna, en particular entre la penitencia de don Quijote y la experiencia literaria moderna, puede pensarse a partir de esta «interpretación figural» $(1998: 99,124)$ estudiada por Auerbach. Estos pasajes de la novela de Cervantes serían «figura» de una realidad aún no consumada en su momento histórico, como es la literatura moderna. En este sentido preciso, la consideración de don Quijote como profeta sería algo más que una mera metáfora. 
efecto de realidad que hace que las manos se nos humedezcan o que no podamos dejar la lectura hasta acabar. La locura de don Quijote es, pues, la de todos nosotros y se llama literatura.

El juego de don Quijote así lo indica: reconoce la identidad concreta de Dulcinea como Aldonza, pero al mismo tiempo hace la afirmación absoluta de su realidad ideal ${ }^{14}$. La situación es exactamente la inversa de la del encantamiento de Dulcinea, en la segunda parte de la obra, episodio que ha sido objeto del famoso estudio de Auerbach. Si en este se trata de la aparición grotesca del ideal en su mostrenca presencia física, aparición que posee un inequívoco efecto cómico — «Para descubrir en esta escena alguna seriedad o un sentido profundo oculto, sería menester violentarla» (Auerbach 1996: 323) - , en Sierra Morena se trata de la presentación del ideal en tanto que tal, palpable en su absolutez por obra y gracia de la fe de don Quijote, aunque impresentable físicamente e irreductible a ninguna presencia concreta. El ideal aparece en una presencia imponente que la existencia misma de Aldonza no puede relativizar: «... bástame a mí pensar y creer que la buena de Aldonza es hermosa y honesta...». Si el encantamiento de Dulcinea tenía un efecto cómico indudable, por el contrario, esta otra afirmación creyente e inventiva de Dulcinea nos alcanza con su seriedad y nos contagia de creencia. Si en el episodio del encantamiento teníamos «el choque (...) con la realidad vulgar y cotidiana, opuesta a toda ilusión» (Auerbach 1996: 316), en el episodio de Sierra Morena tenemos la afirmación verdadera de la ilusión, cifra quizás del descubrimiento cervantino de una «ficción real» (Rodríguez 2003: 142), y encarnada en una Dulcinea que no es la alegoría del absoluto teológico sino la figura del literario ${ }^{15}$.

La manera en que en estos pasajes se reflexiona la experiencia literaria pone en juego la problemática experiencia del absoluto, ausente y presente, parodiado y homenajeado. La autora francesa Marthe Robert vio muy bien cómo la obra de Cervantes, en su relación compleja con los libros de caballerías, proponiéndose al mismo tiempo negar la tradición épica y simularla, pretendía de alguna forma reapropiarse de su carácter de literatura verdadera,

14. Recordemos el extraordinario pasaje del capítulo 25: «Así que, Sancho, por [para] lo que yo quiero a Dulcinea del Toboso, tanto vale como la más alta princesa de la tierra. [...] ... bástame a mí pensar y creer que la buena de Aldonza Lorenzo es hermosa y honesta, y en lo del linaje, importa poco, que no han de ir a hacer la información dél para darle algún hábito, y yo me hago cuenta que es la más alta princesa del mundo. [...] yo imagino que todo lo que digo es así, sin querer que sobre ni falte nada, y píntola en mi imaginación como la deseo, así en la belleza como en la principalidad...» (p. 285).

15. El paralelismo entre Dulcinea y la Beatriz de Dante, señalado por Auerbach (1996: 323), así lo indica. Auerbach (1998) ha mostrado la importancia de la interpretación figural en la Divina comedia, así como la realidad figural de Beatriz, persona de carne y hueso, con realidad histórica, pero dotada del más profundo significado: encarnar la verdad divina, ser figura Christi (Auerbach 1998: 129). Llevando más allá las tesis de Auerbach, podríamos afirmar que la naturaleza de Dulcinea es también figural: personaje real e histórico (Aldonza) que es, sin embargo y al mismo tiempo, encarnación de un absoluto, no teológico sino estrictamente literario, prefiguración de una paradójica consumación futura del mismo. 
dotada de un verdadero poder configurador de realidad y de mundo. La palabra épica poseía una verdad que era la del orden universal mismo y era una palabra que «hablando propiamente, no tiene mensaje que transmitir sino que es ella misma ese mensaje» (Robert 1963: 98). Se trata de la palabra que concede existencia a aquello de lo que habla en virtud de su mismo proferimiento ${ }^{16}$. La palabra épica no está separada de la cosa, no expresa opiniones sobre los acontecimientos o las instituciones, no ofrece interpretaciones, simplemente nombra y se pronuncia y, haciéndolo, funda un orden, establece una legalidad, instituye realidad. De ese modo, la épica aportaba el modelo de una literatura unida a la vida, propiedad que se transmite, según Robert, a toda literatura, y que hace que esta no deje de beber de aquella como de su fuente. La obra de Cervantes habría recogido inauguralmente esa pretensión de la épica, por lo que el Quijote podría considerarse, según Robert, «la nueva Odisea».

Desde esa perspectiva, la tarea heroica de don Quijote consistiría realmente en probar el poder y la verdad de los libros, y representaría la vocación donquijotesca de la literatura moderna. Esta tiene como presupuesto la fe absoluta en la literatura, la creencia de que todos los libros son de algún modo verdaderos, como se dice por boca del bachiller Sansón Carrasco: «No hay libro tan malo - dijo el bachiller-que no tenga algo bueno» (cap. 3, 2. ${ }^{a}$ parte, p. 654). Pero esa vocación, al tiempo que necesaria, se revela imposible porque parte precisamente de la ruptura del orden universal que la épica cantaba y, por tanto, se funda en la certeza de que no hay una Palabra Primera o un Libro Absoluto, en la convicción de que no se puede decir nada que no haya sido ya dicho, por lo que la palabra literaria moderna está abocada a repetirse, multiplicarse y desdoblarse infinitamente. La repetición «funda a la obra como obra única» (Blanchot 1969: 570) y no se va a reducir a la mera imitación de modelos, sino que va a ser para la literatura moderna, como ha visto Blanchot, una estructura más profunda y más inquietante: la obra, estructuralmente afectada por una duplicidad o una distancia con respecto a sí, exige desde sí misma la infinitud de otras palabras que no pueden colmar más que vanamente «la falta que hace hablar a la obra $»^{17}$. Solo en el silencio de

16. «Proferir» es, como recuerda Nancy (2015b: 101), traer ante sí algo, presentarlo y declararlo, en el sentido de «hacer resonar»: «Lo real no es si no resuena en lo irreal». Esa palabra, como la épica, que concede una fe absoluta a lo que cuenta pero al mismo tiempo sabe que todo está contenido en ella misma como palabra, en su proferimiento, es en cierto modo el modelo de la palabra literaria: «No hay en efecto ningún contador, ningún hacedor o recitador de historias, de mitos, de leyendas, de palabras sagradas o de filiación divina, no hay ninguno que no dé a la vez completa credibilidad al cuento y no sepa sin embargo que toda la sustancia de ese cuento reside en su palabra, en su proferimiento, que es también su invención» (Nancy 2015a: 84).

17. «[La obra]...tiende irresistiblemente a volver a decirse, exigiendo esta palabra infinita del comentario en que, separada de sí misma por la bella crueldad del análisis (el cual, en verdad, no la separa arbitrariamente sino en virtud de esta separación que trabaja ya en ella, no-coincidencia que sería su muy ligero palpitar), espera que se ponga fin al silencio que le es propio. Espera naturalmente fallida. La repetición del libro por el comentario es ese movimiento por el cual una nueva palabra, introduciéndose en la falta que hace hablar a la obra, palabra nueva y sin embargo la misma, preten- 
la Palabra plena, en el hueco dejado por su ausencia, puede proliferar esa infinidad material de libros que llamamos literatura ${ }^{18}$.

En los pasajes del Quijote que comentamos tiene a ese respecto un valor ejemplar la maleta encontrada en la sierra y sobre todo el «librillo de memoria» que había dentro. La maleta es algo abierto porque contiene una infinitud depositada en ese librillo. Su dueño es Cardenio pero también don Quijote, de lo que no cabe duda a través de la identificación de ambos. Se podría jugar con la idea de que ese «librillo de memoria» es en cifra la obra literaria moderna. Librillo que remite a la historia que lo precedía, y que en parte se contiene en él, y a la que le sigue: la historia que a retazos e hipotéticamente se derivaba de su contenido, historia contada por Cardenio mismo, que sin embargo queda inacabada la primera vez que la cuenta a causa de la intervención de don Quijote, historia que tiene que esperar a un segundo cuento y que sufre su multiplicación en boca de otros personajes. El recurso de cortar la historia ya había sido usado en el relato del episodio con el vizcaíno, abortado en el momento en que la espada en alto está a punto de caer sobre el contrincante, y retomado a través de la traducción del historiador arábigo Cide Hamete, en el capítulo 9 de la primera parte. Apertura o infinitud del librillo que se prolonga en su utilización por parte de don Quijote como soporte material para escribir la carta a Dulcinea y la «cédula de pollinos» que Sancho debía llevar consigo cuando sale de la sierra; documentos que debía hacer que algún escribano «trasladara» en papel pero que finalmente olvida en la sierra - envío fallido o interrumpido - , lo que le obliga a echar mano de su débil memoria para reconstruir su contenido, con el resultado cómico y disparatado que conocemos.

\section{DON QUIJOTE, FIGURA DEL ESCRITOR MODERNO}

Ya hemos sugerido que don Quijote es de alguna forma el héroe que encarna la vocación literaria moderna y, en ese sentido, su figura es la del escritor. Para acabar, concretemos algo más esta identidad literaria de nuestro protagonista. En los capítulos que comentamos veíamos cómo don Quijote

de rellenarla y colmarla» (Blanchot 1969: 571). Esta caracterización blanchotiana de la obra literaria moderna está expresamente referida al Quijote.

18. Sin atribuir este surgimiento de la literatura moderna a la obra de Cervantes, a quien considera representante de la preliteraria época clásica, Foucault (2013: 101) ha expresado de manera elocuente esta situación que aquí vemos prefigurada en el pasaje que comentamos del Quijote: «La literatura ha comenzado cuando se ha callado para el mundo occidental, para una parte del mundo occidental, ese lenguaje que no había cesado de oírse, de percibirse, de estar supuesto durante milenios. A partir del siglo XIX dejamos de estar a la escucha de esta palabra primera y, en su lugar, se hace oír el infinito del murmullo, la acumulación de las palabras ya dichas; en esas condiciones (...) la obra sólo puede hablar como un lenguaje que repite lo que ha sido dicho y que, por la fuerza de su repetición, a la vez borra todo lo que ha sido dicho y lo aproxima a sí para volver a aprehender la esencia de la literatura». 
construía su identidad especularmente con Cardenio. Su yo era forjado en la experiencia crucial a la que se expone ya que en ella se ve fuera de sí mismo y sale de su interioridad para ponerse en obra. Don Quijote lleva a cabo en su hazaña una verdadera autoposición libre de sí, rompiendo con sus adherencias naturales, familiares o heredadas (Cerezo 2016: 167-198). Hasta podríamos decir que la desnudez de don Quijote en su penitencia es la manera en que se dota a sí mismo de una corporalidad a tono con su identidad libérrima. Don Quijote es hijo de sí mismo, de manera análoga a cómo la novela es declarada huérfana por Cervantes en el prólogo. Pero ahí está también la locura de don Quijote -y quizás la de Cervantes-: solo puede ser comienzo absoluto de sí mismo a condición de desnudarse radicalmente de toda realidad determinada o mundana para poder afirmar un absoluto que solo se le ofrece como desaparecido; esa locura le permite la máxima autoafirmación de sí mismo a través de su radical pérdida, de su existencia desdoblada y repetida hasta el infinito. Tras la afirmación alucinada que don Quijote hace de su propia identidad al comienzo de la obra — «Yo sé quién soy, respondió don Quijote, y sé que puedo ser, no solo los que he dicho, sino todos los Doce Pares de Francia, y aun todos los nueve de la Fama...» (cap. 5, p. 73) — está la afirmación de una identidad, como la del escritor, que encierra en sí misma su repetición o proliferación infinita, lo que hace del escritor un «reescritor» (Barja 2006: 76) y de don Quijote la figura en la que se contienen «todos» los escritores: alguien que antes de empezar a rellenar la página en blanco sabe que su palabra nacerá ya repetidora y repetida - repetición de otras palabras que la anteceden y, a la vez, repetida por otras, que le serán también, de algún modo, anteriores - , palabra pues que es suya y al mismo tiempo de cualquier otro, de cualquiera que, como él, viva y se desviva por ese saber profundo que, como a él, lo salva y lo condena a la vez.

De la condición de escritor que tiene don Quijote en estos pasajes no hay ninguna duda, también es la condición de su alter ego, Cardenio ${ }^{19}$. Pero, más allá de ello, lo que en estos pasajes quizás aparece es la figura del escritor como escritor, del escritor moderno en estado puro. Pero no solo porque escriba versos sino porque funda su identidad en esa fe absoluta en la literatura. Como mostró hace años Jean Krynen (1958), don Quijote no es solo aficionado a la poesía o poeta ocasional, sino que es «ejemplar poeta» en el sentido de que su locura es realmente poética, siendo su causa un desmesurado amor a la poesía que se convierte, de ese modo, en verdad de la vida. Para Krynen, esa locura de don Quijote encarna la actitud moderna del poeta:

19. En el relato que hace Cardenio de su historia, en el capítulo 24: «¡Ay, cielos, y cuántos billetes le escribí! ¡Cuán regaladas y honestas respuestas tuve! ¡Cuántas canciones compuse y cuántos enamorados versos, donde el alma declaraba y trasladaba sus sentimientos, pintaba sus encendidos deseos, entretenía sus memorias y recreaba su voluntad!» (p. 263). Y en el relato que se hace de la penitencia de don Quijote más adelante: «Y lo que le fatigaba mucho era no hallar por allí otro ermitaño que le confesase y con quien consolarse; y, así, se entretenía paseándose por el pradecillo, escribiendo y grabando por las cortezas de los árboles y por la menuda arena muchos versos, todos acomodados a su tristeza, y algunos en alabanza de Dulcinea» (cap. 26, p. 292). 
«Como al poeta moderno, no tanto le interesa realizar una obra de arte sino más bien llevar a cabo una obra vivida, vivir la poesía» (1958: 2). Es exactamente lo que nos enseñaba el episodio de Sierra Morena. La gran hazaña que allí pretendía realizar don Quijote consiste, no tanto en interpretar estéticamente su vida a partir de los modelos literarios, viviendo su vida como una obra de arte, sino en realizar vital y materialmente esos modelos, haciendo de ellos una afirmación absoluta de carácter trascendental, en la que estos sobrepasan y absorben la realidad cotidiana para convertirse en presentación viva de un mundo en la obra literaria, de un mundo que existe y se sostiene por sí mismo. «Don Quijote es poeta en la acción y de la acción», afirmaba Maldonado de Guevara (1973: 176), aunque habría que añadir que el «poeta de acción» es la esencia del poeta o del escritor en general, de la poesía como poiesis por excelencia, según un sentido de la poesía que quizás no fue reflexionado teóricamente hasta el romanticismo ${ }^{20}$. Don Quijote es el profeta de una verdad que aparece realizada materialmente en una forma de vida, la literaria, y que encarnándose en ella, hace visible una vida más verdadera que la común y ordinaria ${ }^{21}$. Su locura es sin duda la del escritor: pasión por lo imposible, creencia plena en una realidad que no existe, salvo en la ficción, pero que se revela como más verdadera que las verdades consabidas, compromiso a muerte con la literatura, acción soberana que está más allá de la vida.

La obra de Cervantes, en este episodio de la penitencia en Sierra Morena, no se limita a formular esta idea, claro está, como si hubiera una tesis filosófica por debajo o por detrás. Como se ha señalado con frecuencia, la modernidad del Quijote está en que introduce al escritor en su obra, convierte en tema de la misma la paradoja del acto de escribir y del hecho literario. La «triste figura» de nuestro penitente enamorado es la figura del escritor absoluto.

\section{BIBLIOGRAFÍA CITADA}

Atlee, A. F. Michael (1986). «Don Quijote: caballero de la triste Idea», Cuadernos hispanoamericanos. 430 , pp. 17-25.

Auerbach, Erich (1996). «La Dulcinea encantada», en Mímesis. La representación de la realidad en la literatura occidental. México: Fondo de Cultura Económica, pp. 314-339. Auerbach, Erich (1998). Figura. Madrid: Trotta.

Avalle-Arce, Juan Bautista (1970). «Don Quijote, o la vida como obra de arte», Cuadernos hispanoamericanos. 242, pp. 247-280.

20. Tal como han mostrado, en su interpretación de los románticos de Jena, Philippe LacoueLabarthe y Jean-Luc Nancy (1978: 21). Ver también, sobre la idea de la poesía como acción por excelencia, Nancy (1997).

21. Quizás se trataría, como ha mostrado Foucault (2009: 172-174), de la reaparición en el arte contemporáneo del tema cínico antiguo de la verdadera vida como forma de vida en que se produce la manifestación concreta y material de la verdad, un «escándalo de la verdad» que toma cuerpo en la vida de artista y en la propia obra de arte moderna, lo que explica el carácter cínico o contracultural que es específico del arte y de la literatura moderna. 
Bardon, Maurice (2010). El «Quijote» en Francia en los siglos XVII y XVIII. Alicante: Universidad.

Barja, Juan (2006). «El yo y los otros. La per-versión como con-figuración», en Félix Duque (ed.), El yo fracturado. Don Quijote y las figuras del barroco. Madrid: Círculo de Bellas Artes, pp. 35-76.

Blanchot, Maurice (1959). «La parole prophétique», en Le libre à venir. París: Gallimard, pp. 109-119.

Blanchot, Maurice (1969). «Le pont de bois (la répétition, le neutre)», en L'entretien infini. París: Gallimard, pp. 568-582.

Blanchot, Maurice (1981). «La littérature et le droit à la mort» (1948), en De Kafka à Kafka. París: Gallimard, pp. 11-61.

Bloom, Harold (1995). El canon occidental. Barcelona: Anagrama.

Cerezo, Pedro (2006) «Las figuras quijotescas de la melancolía», en Félix Duque (ed.), $E l$ yo fracturado. Don Quijote y las figuras del barroco. Madrid: Círculo de Bellas Artes, pp. 211-262.

Cerezo, Pedro (2016). El «Quijote» y la aventura de la libertad. Madrid: Biblioteca Nueva.

Cervantes, Miguel de (1998). Don Quijote de la Mancha. Barcelona: Instituto Cervantes - Crítica.

Chartier, Roger (2010). «¿Cómo leer un texto que no existe? Cardenio perdido», en Actas del XVI Congreso AIH. Madrid: Iberoamericana - Vervuert, pp. 53-74.

Chiong Rivero, Horacio (2006). «"A imitación del hilo del laberinto de Perseo": el nexo narrativo de las ficciones laberínticas en Sierra Morena». Modern Language Notes. 2, pp. 278-298. https://doi.org/10.1353/mln.2006.0056.

Cortázar, Celina S. de (1984). «El Quijote, parodia antihumanista. Sobre literatura paródica en la España barroca», Anales Cervantinos. 22, pp. 59-75.

De la Higuera, Javier (2013). «El Quijote y la melancolía», Arbor. Ciencia, pensamiento y cultura. 189 (760), pp. 1-11. https://doi.org/10.3989/arbor.2013.760n2001.

Duque, Félix (2006). «Ácida comicidad. Don Quijote y el héroe invertebrado», en Félix Duque (ed.), El yo fracturado. Don Quijote y las figuras del barroco. Madrid: Círculo de Bellas Artes, pp. 11-34.

Fernández Turienzo, Francisco (1983). «El "pasaje más oscuro" del Quijote y las ideas estéticas de Cervantes», Anales Cervantinos. 21, pp. 51-72.

Finello, Dominick L. (1980). «En la Sierra Morena: Quijote, I, 23-26», en Actas del VI Congreso AIH. Toronto: University, pp. 242-244.

Foucault, Michel (1994a). «L'arrière-fable» (1966), en Dits et écrits. Vol. I, 1954-1969. París: Gallimard, pp. 506-513.

Foucault, Michel (1994b). «Qu'est-ce qu'un auteur?» (1969), en Dits et écrits. Vol. I, 19541969. París: Gallimard, pp. 789-821.

Foucault, Michel (2009). «Leçon du 29 février 1984», en Le courage de la vérité. Le gouvernement de soi et des autres II. París: Gallimard - Seuil.

Foucault, Michel (2013). «Littérature et langage» (1964), en La grande étrangère. París: École des Hautes Études en Sciences Sociales, pp. 75-144.

García Gibert, Javier (1997). "Cervantes y la melancolía», en Cervantes y la melancolía. Ensayos sobre el tono y la actitud cervantinos. Valencia: Alfons El Magnànim, pp. 65138.

Gerhardt, Mia I. (1955). «Don Quijote. La vie et les livres», Mededelingen der Koninklijke Nederlandse. Akademie van Wetenschappen, Afd. Letterkunde. 2, pp. 17-57.

Herrero, Javier (1981). «Sierra Morena as Labyrinth: From Wildness to Christian Knighthood», Forum for Modern Language Studies. 17 (1), pp. 55-67. https://doi. org/10.1093/fmls/xvii.1.55. 
Hutchinson, Steven (1995). «Las penitencias de Don Quijote y Sancho Panza», en Actas del XII Congreso AIH. Birmingham: University, pp. 292-301.

Jiménez Fajardo, Salvador (1984). «The Sierra Morena as Labyrinth in Don Quixote I», Modern Language Notes. 99 (2), pp. 214-234. https://doi.org/10.2307/2906185.

Krynen, Jean (1958). «Don Quijote, ejemplar poeta», Anales cervantinos. 7, pp. 1-11.

Kundera, Milan (1996). «La desprestigiada herencia de Cervantes», en El arte de la novela. Barcelona: Círculo de Lectores, pp. 13-30.

Lacoue-Labarthe, Philippe y Jean-Luc Nancy (1978). L'absolue littéraire. Théorie de la littérature du romantisme allemand. París: Seuil.

Maldonado de Guevara, Francisco (1973). «El furor y la furia», Anales cervantinos. 12, pp. $175-177$.

Márquez Villanueva, Francisco (2011). Personajes y temas del Quijote. Barcelona: Bellaterra.

Nancy, Jean-Luc (1997). «Faire, la poésie», en Resistance de la poésie. Burdeos: William Blake \& co., pp. 9-15.

Nancy, Jean-Luc (2015a). «... devrait être un roman» (2012), en Demande. Littérature et philosophie. París: Galilée, pp. 79-86.

Nancy, Jean-Luc (2015b). «Pour ouvrir le libre» (2013), en Demande. Littérature et philosophie. París: Galilée, pp. 97-102.

Ortega y Gasset, José (2001). Meditaciones del Quijote (1914). Madrid: Cátedra.

Pagán, Flor María (1997). «Geografía, ansiedad e ‘imitatio’ en la penitencia de la Sierra Morena», Neophilologus. 81 (4), pp. 551-562.

Resina, Joan Ramón (1989). «Medusa en el laberinto: locura y textualidad en el Quijote», Modern Language Notes. 104 (2), pp. 286-303. https://doi.org/10.2307/2905140.

Riley, Edward C. (1989). Teoría de la novela en Cervantes. Madrid: Taurus.

Riley, Edward C. (2000). Introducción al "Quijote". Barcelona: Crítica.

Robert, Marthe (1963). «La nouvelle Odyssée», en L'Ancien et le nouveau. De Don Quichotte à Franz Kafka. París: Grasset, pp. 55-172.

Rodríguez, Juan Carlos (2003). El escritor que compró su propio libro. Para leer «El Quijote». Barcelona: Debate.

Salinas, Pedro (1989). «La mejor carta de amores de la literatura española», Anthropos. Boletín de información y documentación. Extra 16, pp. 118-124.

Sánchez, Alberto (1989). «El capítulo XXV del primer Quijote (1605), clave sinóptica de toda la obra», Crítica hispánica. XI, pp. 95-113.

Sánchez, Alberto (1999). «Lecturas del Quijote. Primera parte. Capítulo XXIII», en Don Quijote de la Mancha. Volumen complementario. Barcelona: Instituto Cervantes Crítica, pp. 64-65.

Schlegel, Friedrich (1994). Poesía y filosofia, Diego Sánchez Meca y Anabel Rábade Obradó (trads.). Madrid: Alianza.

Thiebaut, Carlos (2016). «Piedad y melancolía (Montaigne y Cervantes en la muerte de Don Quijote)», en Roberto Rodríguez Aramayo, José Francisco Álvarez, Francisco Maseda y Concha Roldán (eds.), Diálogos con Javier Muguerza. Paisajes para una exposición virtual. Madrid: CSIC, pp. 561-584.

Torrente Ballester, Gonzalo (1975). El «Quijote» como juego. Madrid: Guadarrama.

Unamuno, Miguel de (1988). Vida de Don Quijote y Sancho (1905). Madrid: Cátedra.

Yushimito del Valle, Carlos (2010). «La armadura en el espejo: Encuentro de don Quijote y Cardenio o la construcción especular de la identidad del héroe en el episodio de Sierra Morena (I, 23-26)», Espéculo. Revista de estudios literarios. 44, s.p.

Recibido: 30 de octubre de 2017

Aceptado: 18 de diciembre de 2017 